\title{
ACOMPANHAMENTO FARMACOTERAPÊUTICO DE PACIENTES ODONTOLÓGICOS PORTADORES DE DIABETES MELLITUS
}

\section{PHARMACOTHERAPEUTIC MONITORING OF DENTAL PATIENTS WITH DIABETES MELLITUS}

\author{
Miguel, Y. D. ${ }^{1} ;$ Jesus, C. C. ${ }^{2}$; Kerber, V. A. ${ }^{3}$; Krause, M. S. ${ }^{4} ;$ Oliveira, V. B. ${ }^{4}$
}

\author{
${ }^{1}$ Aluna de graduação de odontologia da UFPR, \\ ${ }^{2}$ Aluna de graduação de farmácia da UFPR, \\ ${ }^{3}$ Professor doutor do curso de farmácia da UFPR, \\ ${ }^{4}$ Aluna/o de doutorado do programa de Pós-Graduação em Ciências Farmacêuticas. \\ Email:vinicius.bednarczuk@hotmail.com
}

\section{RESUMO}

A diabetes é uma das doenças mais comumente encontradas na população, a qual resulta de um grupo de distúrbios metabólicos devido a falta de insulina ou da mesma não exercer sua função adequadamente, gerando alta taxa de glicose no sangue. Uma das complicações da diabetes é a doença periodontal, a qual é uma doença crônica consequência da infecção bacteriana nos tecidos de suporte dos dentes, tendo como etiologia primária o biofilme dental. Entre os pacientes odontológicos $3-4 \%$ deles possuem diabetes. $\mathrm{O}$ objetivo deste trabalho foi analisar, por meio de um instrumento de avaliação contendo 10 perguntas, no período de fevereiro a junho de 2013, os conhecimentos e condutas entre os acadêmicos de odontologia da Universidade Federal do Paraná sobre a relação entre o diabetes e a doença periodontal incluindo o tratamento farmacoterapêutico. Dentre os resultados encontrados pode-se evidenciar a importância do tema para saúde pública e a necessidade de se investir na formação acadêmica dos futuros profissionais, além da percepção por parte do odontólogo a necessidade de um acompanhamento multiprofissional e interdisciplinar do paciente. Estes devem conhecer a diabetes, seus principais sintomas, as manifestações bucais e medicamentos utilizados para prevenir e combater infecções que possam descompensar os níveis glicêmicos do paciente, evitando o comprometimento sistêmico do indivíduo. Além das possíveis interações entre os medicamentos no controle da diabetes e os medicamentos usados no tratamento da doença periodontal. Palavras-chaves: Interdisciplinaridade em saúde, Diabetes mellitus, Doença Periodontal.

\section{ABSTRACT:}

Diabetes is one of the most commonly encountered diseases in the population, which results in a group of metabolic disorders due to lack of insulin or it does not perform its function properly, causing a high rate of blood glucose. One of the complications of diabetes is periodontal disease, which is a consequence of chronic bacterial infection of the tissues supporting the teeth, with the primary etiology dental biofilm. Between 3-4 \% of dental patients have diabetes. The objective of this study was to analyze, by means of an assessment instrument containing 10 questions, in the period from February to June 2013, the knowledge and behavior among dental students at the Federal University of 
Paraná on the relationship between diabetes and periodontal disease including pharmacotherapeutic treatment. Among the findings can highlight the importance of the issue for public health and the need to invest in the academic training of future professionals, beyond perception by the dentist the need for a multidisciplinary and interdisciplinary patient monitoring. They should know the diabetes, its main symptoms, oral manifestations, and drugs used to prevent and fight infections that may decompensate the patient's glucose levels, avoiding the systemic involvement of the individual. In addition to the possible interactions between the drugs in controlling diabetes and medications used in the treatment of periodontal disease.

Key words: Interdisciplinary in health, Diabetes mellitus, Periodontal Disease

\section{INTRODUÇÃO}

Diabetes é uma doença metabólica resultante da diminuição, falta, e problemas na secreção ou absorção de insulina. Nestas situações o metabolismo da glicose não ocorre satisfatoriamente, gerando uma alta taxa de glicose no sangue. Existem dois tipos mais recorrentes da doença, o diabetes mellitus tipo 1 (DM1) é decorrente da destruição das ilhotas de Langerhans do pâncreas, o que impede a produção de insulina, causando uma deficiência absoluta do hormônio. O tratamento com insulina é indispensável para todos os portadores deste tipo de diabetes. Quando o quadro clínico se inicia já ocorreu à perda de $80-90 \%$ da capacidade de produção de insulina. O diabetes mellitus tipo 2 (DM2) é caracterizado por resistência a insulina e afeta, principalmente, indivíduos obesos, pois a obesidade acarreta em resistência periférica da ação deste hormônio (ROSA, 2010). Quando pacientes com DM2 não conseguem atingir níveis aceitáveis de glicose no sangue com o uso de hipoglicemiantes orais, estes devem fazer o uso da insulina (SOUZA et al., 2003).

A hiperglicemia causada pelo mau controle da doença é um fator de risco para infecções, pois favorece o crescimento de microbiota patogênica (ROSA, 2010). Aproximadamente $75 \%$ dos diabéticos, que não fazem o controle da glicemia, possuem doença periodontal (TERRA et al., 2011). Adoença periodontal é uma doença crônica que ocorre devido à infecção bacteriana nos tecidos de suporte dos dentes, que pode ser na forma mais branda chamada gengivite ou mais severa na periodontite. O biofilme dental que se acumula no sulco gengival e ao redor dos dentes é o agente etiológico primário, levando a perda dos tecidos de suporte, ligamento periodontal e osso, até a consequente perda do elemento dentário. Sendo assim, sua manifestação inicial é a gengivite, caracterizada por hiperemia, edema, recessão e sangramento gengival. Se não tratada, pode evoluir para periodontite, levando a formação da bolsa gengival (ALVES et al., 2007).

A relação entre diabetes e doença periodontal é muito discutida, a maior prevalência, extensão e severidade da doença periodontal em indivíduos portadores de diabetes foi comprovada em diversos estudos e pode ter relação com o controle 
metabólico. Desta forma, indivíduos com metabolismo descompensado podem ter maior inflamação gengival, maior perda de inserção periodontal e óssea ao compararmos com pacientes metabolicamente sadios (NERY, C.F., 2008).

Visto isso, foi realizada uma pesquisa com os acadêmicos do curso de odontologia da Universidade Federal do Paraná, para verificar o conhecimento dos mesmos quanto a diabetes relacionada à doença periodontal, e os cuidados a serem tomados com o paciente durante o tratamento.

\section{METODOLOGIA}

A pesquisa, aprovada pelo comitê de ética, foi realizada por meio de entrevistas contendo questões abertas propostas aos acadêmicos de odontologia da Universidade Federal do Paraná. Os acadêmicos de Odontologia participantes são do $9^{\circ}$ período, os quais já cursaram as disciplinas Periodontia, Semiologia e Farmacologia. Foram analisados 15 questionários. Os dados coletados a partir das entrevistas foram submetidos à análise percentual e os resultados obtidos correlacionados com dados da literatura.

O modelo de entrevista aplicado aos acadêmicos de odontologia está abaixo:

\section{QUADRO 1: Modelo de entrevista para acadêmicos de odontologia}

1- O que é diabetes e quais são seus principais sintomas?

2 - Quais são os tratamentos usualmente utilizados para tratar à diabetes?

3 - O que é doença periodontal e qual a sua relação com a diabetes?

4 - Quais são os sintomas da doença periodontal?

5 - Quais questionamentos você realiza ao paciente quando este chega a uma consulta odontológica?

6 - Para o atendimento de diabéticos (realização de procedimentos odontológicos) há alguma conduta específica? $Q$ uais os cuidados que devem ser tomados durante 0 atendimento?

7 - Você sabe identificar uma crise hiper ou hipoglicêmica? Qual é a conduta que deve ser tomada nestes casos?

8 - Quais são os tratamentos medicamentosos empregados para a doença periodontal?

9 - Você sabe quais são os antibióticos mais prescritos para tratar a doença periodontal? Existe algum antibiótico que não deve ou deve ser utilizado com cautela em diabéticos?

10 - Você sabe quais são os antiinflamatórios mais prescritos para tratar a doen ça periodontal? Existe algum antiinflamatório que não deve ou deve ser utilizado com cautela em diabéticos? 


\section{RESULTADOS E DISCUSSÃO}

De acordo com as diretrizes da Sociedade Brasileira de diabetes (2009), a diabetes é um distúrbio metabólico caracterizado por hiperglicemia a qual é decorrente do defeito na ação e/ou secreção da insulina. Ao questionar acadêmicos de odontologia, sobre o que é diabetes foi obtido $87 \%$ de respostas corretas (gráfico 1). Os sintomas mais precoces da diabetes incluem a poliúria, polidipsia, polifagia (aumento da fome), perda de peso e astenia, dentre os entrevistados $67 \%$ responderam corretamente, citando pelo menos um dos principais sintomas e $20 \%$ não souberam responder corretamente (gráfico 2). Também foram citadas deficiências visuais, dificuldade na cicatrização, presença de hálito cetônico e tontura. É importante que cirurgiões-dentistas saibam identificar os sintomas do diabetes para que possam orientar seus pacientes a procura de um médico para avaliação e tratamento da doença.

GRÁFICO 1: O que é diabetes.

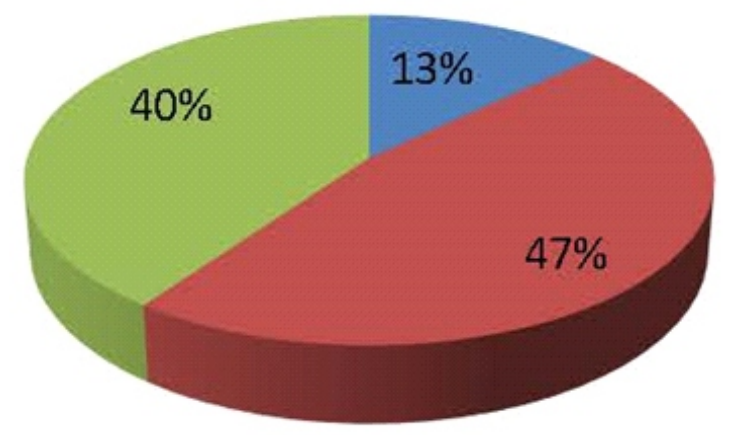

corretas

incompletas

erradas

GRÁFICO 2: Sintomas de diabetes.

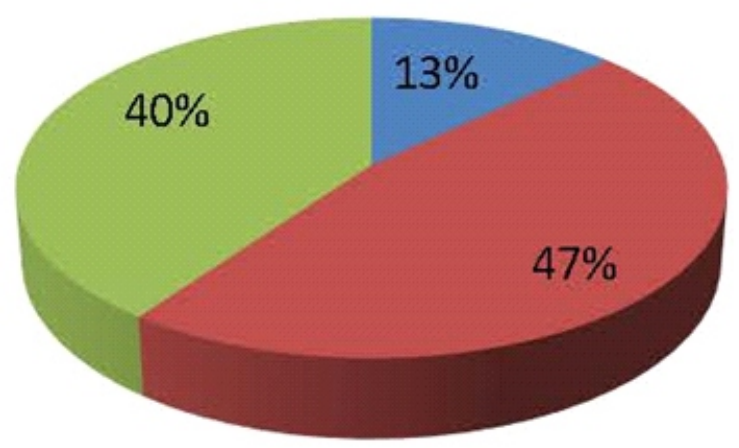

corretas

- incompletas

erradas 
O tratamento adequado do diabetes contempla reeducação alimentar,prática de exercícios físicos e farmacoterapia - utilização de insulina e/ou hipoglicemiantes orais, além de interromper o uso do cigarro (ROSA, 2010). De acordo com essas informações, $47 \%$ responderam corretamente quais os tratamentos da diabetes e $53 \%$ tiveram respostas incompletas (gráfico 3). Deve-se reforçar ao paciente os cuidados especiais que ele deve ter no controle do diabetes para que sua condição sistêmica esteja boa, para uma vida saudável e para realização de procedimentos odontológicos.

GRÁFICO 3: Quais os tratamentos do diabetes.

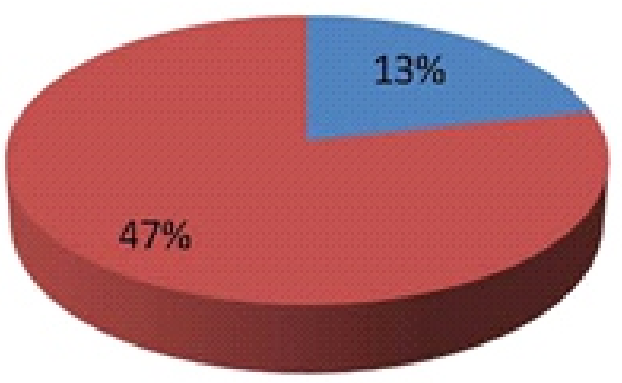

corretas

incompletas

A doença periodontal é uma doença crônica devido à infecção bacteriana nos tecidos de suporte dos dentes, podendo ser da forma mais branda chamada gengivite e mais agressiva na periodontite. Seus sinais são hiperemia, edema, recessão e sangramento gengival e formação de bolsas periodontais. Na entrevista, $67 \%$ dos entrevistados soube dizer corretamente a definição de doença periodontal e apenas $6 \%$ respondeu incompletamente (gráfico 4 ). E todos os alunos souberam dizer os sintomas da doença periodontal, citando também mau hálito e mobilidade dentária.

GRÁFICO 4: O que é a doença periodontal.

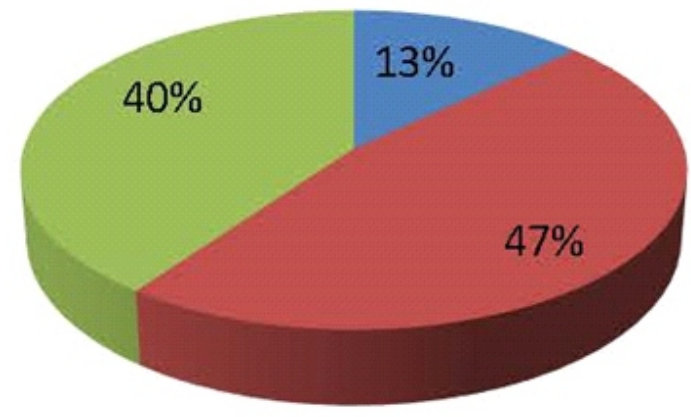

corretas

incompletas

erradas 
O espessamento dos vasos do periodonto causado pela diabetes dificulta o transporte de elementos nutritivos aos tecidos, fazendo-os mais vulneráveis aos produtos de agressão microbiana e maior severidade da doença (MADEIRO et al, 2005). Nos pacientes diabéticos que fazem uso de insulina estão presentes alterações vasculares na gengiva, facilitando a maior frequência da doença periodontal. Outra relação entre diabetes e doença periodontal ocorre por meio da saliva, a qual é um dos principais fatores de defesa da boca, porém os pacientes diabéticos possuem diminuição do fluxo salivar e alteração em seu conteúdo. Foi obtido $47 \%$ de respostas corretas, pelos alunos entrevistados, quanto a relação de diabetes e doença periodontal e $40 \%$ das respostas foram incompletas (gráfico 5). Ter conhecimento sobre essa relação auxilia na prevenção do aparecimento da doença periodontal em pacientes diabéticos e também do tratamento da doença, já que a presença da doença periodontal pode agravar a condição sistêmica do paciente diabético.

GRÁFICO 5: Relação entre a doença periodontal e o diabetes.

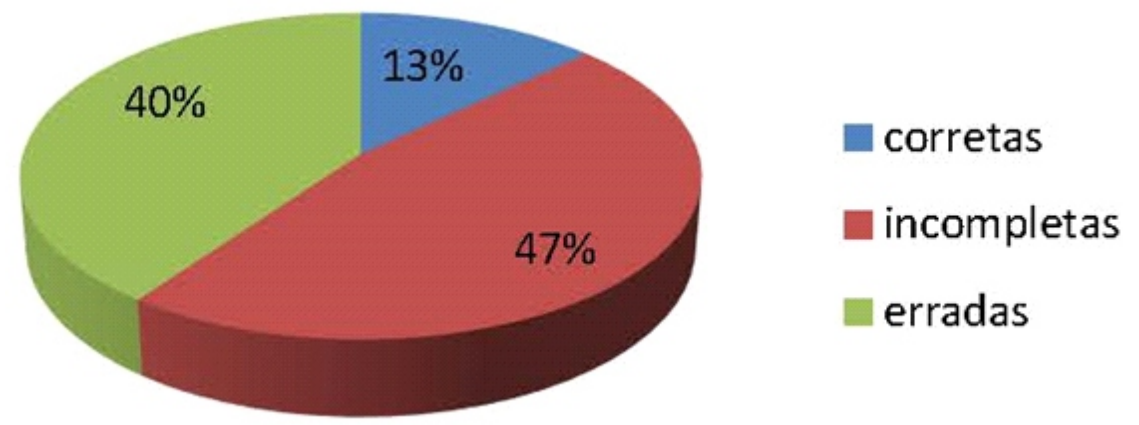

Uma adequada anamnese deve ser realizada no primeiro atendimento ao paciente odontológico. Quando se identifica o portador do diabetes, alguns cuidados específicos devem ser realizados. O Conselho Federal de Odontologia (CFO) fornece um modelo de ficha clínica para anamnese com perguntas importantes que se deve fazer ao paciente. Muitas doenças sistêmicas têm seus primeiros sintomas na região bucal, o que faz do cirurgião dentista um importante instrumento de identificação precoce e orientação para o paciente.

Os principais questionamentos feitos pelos alunos durante a consulta odontológica foram se o paciente possui alguma alergia, quais suas doenças sistêmicas e quais doenças eram presentes na família, seu histórico médico, hábitos de higiene e alimentares, quais os medicamentos utilizados pelo paciente, se faz uso de cigarro, bebidas e/ou drogas e também o histórico odontológico. Já para os cuidados específicos, os alunos disseram ser importante verificar se o paciente está com o diabetes controlado, se ele alimentou-se antes da consulta, realizar um breve 
atendimento e durante a manhã, priorizar as infecções e inflamações, ter atenção na escolha da anestesia e cuidados assépticos, indicar acompanhamento médico ao paciente e atentar para a medicação utilizada.

De acordo com a literatura, durante a anestesia, deve-se optar pelo anestésico prilocaína com felipressina, além de ser evitado o uso de vasoconstritores do grupo das catecolaminas (adrenalina, noradrenalina e levonordefrina) em pacientes alterados metabolicamente. Outro cuidado é o atendimento ser realizado durante a manhã justificado pelo fato de neste período os níveis endógenos de corticosteroide serem geralmente altos, e os procedimentos estressantes podem ser mais bem tolerados (SANTOS et al., 2010.). Deve-se também atentar para a medicação utilizada pelo paciente, para evitar interações medicamentosas e outras consequências.

O quadro clínico da hiperglicemia consiste em polidipsia, poliúria, enurese, hálito cetônico, fadiga, visão turva, náuseas e dor abdominal, além de vômitos, desidratação, hiperventilação e alterações do estado mental. No tratamento deve-se realizar hidratação oral e encaminhamento ao médico para medicação adequada rapidamente. Os sintomas da hipoglicemia podem ser adrenérgicos (taquicardia, tremores, sudorese, palidez) ou neuroglicopênicos (leve alteração do sensório ou do comportamento até convulsões ou coma), e em quadros de hipoglicemia o paciente deve ingerir açúcar. Casos de hiper e hipoglicemia podem ser muito comuns no consultório odontológico durante o atendimento, principalmente em pacientes portadores de diabetes.

É essencial os alunos e profissionais da odontologia saberem identificar e como agir em situações como essas. Os alunos ao serem questionados se sabiam identificar uma crise de hiper ou hipoglicêmica e como trata-las, tiveram $13 \%$ das respostas corretas e $47 \%$ incompletas (gráfico 6). Esse resultado mostra a necessidade de um maior conhecimento sobre esse tema pelos alunos do último semestre de odontologia da UFPR.

GRÁFICO 6: Sabe identificar uma crise hiperglicêmica e hipoglicêmica e qual seu tratamento.

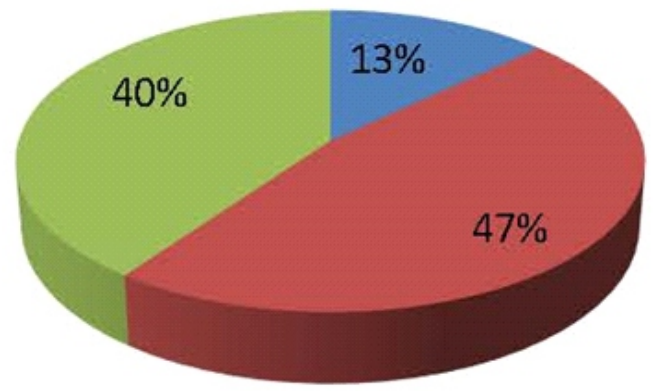

corretas

incompletas

erradas 


\section{CONCLUSÃO}

Diante dos resultados encontrados na pesquisa pode-se observar a importância da inserção, na formação acadêmica, de conteúdos sobre o atendimento de pacientes portadores de diabetes e o conhecimento farmacoterapêutico específico ao tratamento da doença periodontal nesses pacientes. A formação deve proporcionar aos acadêmicos uma visão interdisciplinar oportunizando também uma integração multiprofissional com os demais cursos da saúde, para que assim os pacientes recebam um atendimento mais completo.

Foi observado a necessidade de uma maior abordagem durante o curso daqueles conteúdos referentes à farmacoterapia para o tratamento do diabetes, além dos cuidados específicos necessários para o atendimento odontológico dos mesmos.

\section{REFERÊNCIAS}

ALVES, C.; ANDION, J.; BRANDÃO. M.; MENEZES R. Mecanismos patogênicos da doença periodontal associada ao diabetes mellitus Arq Bras Endocrinol Metab vol.51 no.7 São Paulo Oct. 2007

ALVES, D. G.; Diabetes e Doença Periodontal Trabalho de monografia, UNICAMP. 2006.

ANDRADE, E. D.; Cuidado com o uso de medicamentos em diabéticos, hipertensos e cardiopatas Anais do $15^{\circ}$ Conclave Odontológico Internacional de Campinas ISSN 1678-1899-n.104 - Mar/Abr - 2003

GUYTON, A. C.; HALL, J. E. Tratado de Fisiologia Médica. 10. ed. Rio de Janeiro: Guanabara Koogan, 2002.

MADEIRO, A. T.; BANDEIRA, F. G.; FIGUEIREDO, C. R. L. V.; A estreita relação entre diabetes e doença periodontal inflamatória Odontologia. Clín.-Científ., Recife, 4 (1): 07-12, jan/abr., 2005

MADEIRO, A. T.; PASSOS, I. A.; FIGUEIREDO, C. R. L. V.; Abordagem preventiva da doença periodontal no paciente diabético: Revisão da literatura Revista de Odontologia da Universidade Cidade de São Paulo 2008 jan-abr; 20(1):76-81

MINISTERIO DA SAÚDE Brasil. Ministério da Saúde. Secretaria de Atenção à Saúde. Departamento de Atenção Básica. Diabetes Mellitus (2. ed.) Brasília, 2013 [no prelo]. 
NERY, C. F.; Diabetes e a relação com as doenças periodontais Revista PerioNews 2008;2(3):178-83

ROSA, R. B. A. Atendimento odontológico a pacientes diabéticos com doença periodontal na atenção primária a saúde. Itabira, 2010. Trabalho de Conclusão de curso (Especialização atenção básica saúde da família) - Faculdade de Medicina, Universidade Federal de Minas Gerais.

SANTOS, M. F.; NASCIMENTO, E. M.; PINTO, T. C. A.; LINS, R. D. U.; COSTA, E. M. D. M.; GARCIA, A. F. G. Abordagem odontológica do paciente diabético um estudo de intervenção. Odontol. Clín.-Cient., Recife, 9 (4)319-324, out./dez., 2010

SASAKI R. T.; RAMACCIATO, J. C.; CUNHA, F. L.; CECANHO, R.; TOFOLI, G. Verificação glicêmica casual de pacientes odontológicos RGO P. Alegre, v. 54, n. 2, p. 107-110 abr./jun. 2006

SEABRA, F. R. G.; SEABRA, B. G. M.; SEABRA, E. G. Antibioticoterapia profilática em cirurgias periodontais Odontologia. Clín.-Científ., Recife, 3 (1): 11 -16, jan/abr., 2004

SOARES, R; G.; SALLES, A. A.; IRALA, L. E. D.; LIMONGI, O.; How to choose the adequate local anestheticsnfor different situations on everyday dentistry? RSBO v. 3, n. 1,2006

SPONCHIADO, S.; A inter-relação da doença periodontal e diabetes mellitus. Trabalho de monografia. UNINGÁ. 2007.

SOUSA, R. R.; CASTRO, R. D.; MONTEIRO, C. H.; SILVA, S. C.; NUNES, A. B; O Paciente Odontológico Portador de Diabetes Mellitus: Uma revisão de Literatura Pesq Bras Odontoped Clin Integr, João Pessoa, v. 3, n. 2, p. 71-77, jul./dez. 2003

TERRA, B. G.; GOULART, R. R.; BAVARESCO, C. S.; O cuidado odontológico do paciente portador de diabetes mellitus tipo 1 e 2 na Atenção Primária à Saúde Rev APS. $2011 \mathrm{abr} / \mathrm{jun} ;$ 14(2): 149-161. 